\title{
The mental health of graduate students at the Federal University of São Paulo: a preliminary report
}

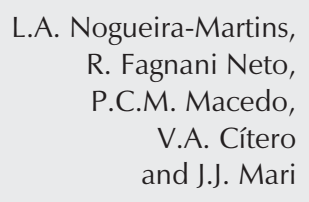

L.A. Nogueira-Martins, R. Fagnani Neto, P.C.M. Macedo,

V.A. Cítero and J.J. Mari

Departamento de Psiquiatria, Universidade Federal de São Paulo, São Paulo, SP, Brasil

\section{Correspondence \\ L.A. Nogueira-Martins \\ Departamento de Psiquiatria \\ Universidade Federal de São Paulo \\ Rua Botucatu, 740, 3음 andar \\ 04023-900 São Paulo, SP \\ Brasil \\ E-mail: \\ nogmartins@psiquiatria.epm.br}

J.J. Mari is a CNPq I-A Researcher.

Publication supported by FAPESP.

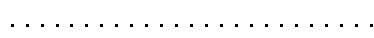

Received January 5, 2004

Accepted July 12, 2004

\begin{abstract}
We present data regarding the care provided to graduate level health professionals at the mental health center of the Federal University of São Paulo. From September 1996 to September 2003, 146 graduate students (99 in the Master's degree program and 47 in the Doctoral program) were attended. This population was predominantly female $(68.5 \%)$, with a mean $( \pm \mathrm{SD})$ age of $28.6 \pm 4.42$ years, not married (71.9\%). Most of the subjects were professionals who had not graduated from the Federal University (78.1\%). The students who sought help for psychological and/or psychiatric problems were classified into two categories: situational-adaptive crises and psychopathological crises. The main diagnoses were depression and anxiety disorders (44\%) causing $4.5 \%$ of the subjects to be temporarily suspended from their graduate studies; $19.2 \%$ reported that they had used psychotropic drugs within the previous month, and $47.9 \%$ referred to sleep disturbances. Suicidal tendencies were mentioned by $18 \%$ of those interviewed. Students with emotional disturbances and academic dysfunctions should be recognized at an early stage, and it is fundamental for them to have access to mental health programs that provide formal, structured and confidential care. Thus, it is important that professors and advisors in graduate programs build a warm and affective learning environment. If we consider the expressive growth in Brazilian scientific production resulting from the implementation of an extensive national system of graduate education, it is important to focus efforts on enhancing and upgrading the mental health care system.
\end{abstract}

Key words

- Mental health

- Graduate education

- Burnout

- Suicide

- Occupational stress

- Mental health program
A high prevalence of suicides, depression, abusive use of psychotropic drugs, stress, burnout, and professional dysfunctions among physicians and especially high rates of stress and depression among medical residents have been extensively described (1-4). There are also data pointing to a high level of stress among graduate students (57), which highlights the fact that physicians taking graduate courses apparently seem to be a subgroup with a greater burden of stress when compared to other graduate students (5).

Recently, de Meis et al. (7), based on 
interviews with 118 individuals in a Department of a Brazilian university (graduate students, postdoctoral fellows and professors), drew attention to the level of stress engendered by the conflict between increasing competition and diminishing resources that has been taking place in recent years in the domain of Brazilian science. Highlighting the positive aspect in the expressive growth of national scientific production, the authors express their concern about the impact of this situation on the individual. According to the authors, $21 \%$ of the people interviewed needed at least one psychiatric visit or psychological therapy and over half of these required a demanding professional followup.

In the present study we report data referring to the care provided to graduate students at a mental health center during the period from September 1996 to September 2003, at the Federal University of São Paulo. The mental health center is part of a health service that has existed for many years - the Health Service for the Student Body - and which provides medical and dental care to the university's student body. Originally established to care for medical residents and the nursing staff, and known as NAPREME (Center for Assistance and Research in Medical Residency), the spontaneous institutional demand for the service soon after its creation meant that it also had to begin attending to the needs of graduate students. The medical care available includes psychotherapy and psychiatric assessment and follow-up carried out by a professional team consisting of two psychiatrists and two psychologists.

The decision to develop a mental health program for graduate students was influenced by three main factors: the suicide of four young physicians at this institution between 1995 and 1996 (two graduate students and two residents), a research study that investigated stress among medical residents (8), and the experience of other countries in response to similar problems (9). In a previ- ous paper we explained the fundamental reasons for the establishment of this program, and the aims and strategies adopted for intra-institutional dissemination (10).

The Federal University of São Paulo offers teaching and training in the health area to some 1,296 undergraduate students (676 in medicine, 115 in biomedical sciences, 317 in nursing, 132 in speech therapy, and 56 in ophthalmic technology). There are 68 nursing residents, 436 medical residents, 1,560 fellows, and 2,451 graduate students stricto sensu. In 2003, there were 1,355 science Master's students and 1,196 Doctoral students enrolled in 39 graduate programs. Until September 2003, 146 graduate students were served by NAPREME.

The graduate student seen at the mental health program has his/her data recorded on a semi-structured registration form. This record contains the patient's demographic data, information on his/her professional training, psychiatric and personal background (gender, age, marital status, how they were referred to the program, recent use of medicines, habits regarding tobacco, alcohol and drugs, suicidal tendencies, previous psychological/psychiatric treatment, main diagnoses, and leaves from activities). The psychiatric diagnoses were made by the psychiatric team on the basis of the ICD-10 criteria.

During the period from September 1996 to September 2003, 146 graduate students were interviewed. Of these 99 were enrolled in the Master's program and 47 in the Doctoral program. This was a predominantly female population, $100(68.5 \%)$, with a mean $( \pm$ SD) age of $28.6 \pm 4.42$ years, single, 105 $(71.9 \%)$, consisting mainly of professionals who had not graduated from the Federal University (78.1\%). Of these, $50(34.5 \%)$ were biomedics, 31 (21.4\%) biologists, 21 $(14.3 \%)$ pharmacists, $9(6 \%)$ speech therapists, 9 (6\%) nutritionists, 7 (4.8\%) physicians, 7 (4.8\%) psychologists, 7 (4.8\%) chemists, and $5(3.6 \%)$ nurses. Most of them, 114 (78\%) were taking courses in the basic areas. 
The molecular biology program $21(14.1 \%)$, immunology 21 (14.1\%), pharmacology 19 $(12.9 \%)$, and nutrition $10(7 \%)$ were the most representative. The desire for assistance from the mental health program was predominantly spontaneous $101(69.2 \%)$, with significant compliance with treatment $98(67 \%)$. There was a high concentration of attendance during the program's first year, involving $82(56 \%)$ of graduate students in the Master's program. Of these, 28 (19.2\%) reported having used psychotropic drugs within the previous month, $83(56.8 \%)$ stated that they had not drunk alcohol, and 20 (13.7\%) were smokers; 70 (47.9\%) referred to some sort of sleep disorder and suicidal tendencies were mentioned by $26(18 \%)$ of those interviewed. Some 50 (34\%) referred to prior psychological/psychiatric treatment, with a history of psychiatric problems in the families of $32(22 \%)$ of these persons. The main diagnoses were depression and anxiety disorders (Table 1), and as a consequence 7 $(4.5 \%)$ were granted temporary leave from the activities of their graduate program.

During treatment the main complaints manifested themselves in a broad and diffuse manner, with most of the students referring to a state of discomfort and despondency regarding their responsibilities, with perceptions/sensations of incompetence and of feeling lost and anxious with regard to their research. Their complaints and somatic problems referred to headaches, stress and muscular pain, constant colds, allergies, difficulties in sleeping, and appetite dysfunctions, which led some of them to frequently seek clinical care at the Health Service for the Student Body.

Regarding situational/occupational stress, one of the points highlighted by several students concerned financial difficulties, particularly for those students in the basic areas. Restrictions and difficulties were due to the fact that most of them had a single source of income - a governmental fellowship for graduate studies - and because of legal re- quirements and limitations inherent to their professional activity, they could not obtain alternative sources of income. Another aspect emphasized by several students was the problems faced because of lack of resources (material, equipment, reagents) to carry out research and the need to follow complicated and difficult procedures in the search for funding. The lack of physical space in laboratories and scarcity of equipment and computers, which forced them to share and dispute space, was also highlighted as a stressful work condition, one that generates conflict with other colleagues. Difficulties in the relationship with research advisors was also one complaint and several students referred to advisors as being inaccessible (not available to meet with students), insensitive and authoritarian.

As attention to the situation occurred and developed, more specific issues appeared including prejudice, styles, personal attitudes and reactions, such as personality characteristics with depressive tendencies. Gradually ways of dealing with difficulties and frustrations, and confrontation strategies were de-

Table 1. The distribution of psychiatric diagnoses of graduate students at the Federal University of São Paulo (1996-2003).

\begin{tabular}{lrr}
\hline Diagnoses & N & $\%$ \\
\hline Adjustment disorders - depressive type (F 43.2) & 29 & 19.9 \\
Depressive episode mild (F 32.0) & 16 & 10.9 \\
Depressive episode moderate (F 32.1) & 12 & 9.2 \\
Somatoform disorders (F 45) & 5 & 3.4 \\
Eating disorders (F 50) & 5 & 3.4 \\
Depressive episode severe (F 32.2) & 4 & 2.7 \\
Anxiety and depression mixed episode (F 41.2) & 4 & 2.7 \\
Obsessive-compulsive disorder (F 42) & 4 & 2.7 \\
Mixed disturbance of emotions and conduct (F 92) & 4 & 2.7 \\
Phobic-anxiety disorder (F 40) + sedative-hypnotic & 4 & 2.7 \\
conduct disorder (F 13) & & \\
Substance abuse (F 55) & 3 & 2.1 \\
Schizotypal disorder (F 21) & 2 & 1.3 \\
Transient acute psychotic episode (F 23) & 1 & 0.7 \\
Other diagnoses & 5 & 3.4 \\
No diagnosis & 48 & 32.8 \\
Total & 146 & 100 \\
\hline
\end{tabular}

Diagnosis was based on ICD-10 criteria. 
veloped, as well as coping with the individual impact of stressful factors, which are inherent to the process of training professors and researchers.

The first year in both the Master's and Doctoral programs was the period with the highest rate of referrals. These data are particularly relevant, indicating to the managers of the health training program for graduate students that they should be much more cautious in the attention devoted to trainees during the first year of any graduate program.

The higher percentage of women in the student population who made use of the mental health program can be looked upon as a reflection of the growing participation of females in the health profession, as well as the greater tendency of women to develop depressive and emotional disorders during training (4). It is also a fact that a higher percentage of women tend to look for medical assistance than men (11), to present higher psychiatric morbidity (12) and to make more use of tranquilizers (13).

The prevalence of disorders in the anxiety-depressive range was observed. This was a finding also reported by Borenstein (9) at a mental health assistance service directed at interns, residents and fellows at the University of California - Los Angeles. As can be seen in Table 1, one third of the cases had no definite psychiatric diagnosis. The more appropriate diagnosis seems to have been that of "a transitory self-limited de-adaptation". It is worthwhile to remember that often most of the problems confronted during training can be overcome with the help of a "mentor", a more experienced individual (or one who is better adapted) and who can be empathic and can offer support to the other. These data reinforce the importance and need to try to create an atmosphere of learning and work that will facilitate communication between students, professors and advisors.

One (1\%) of the students seen during this period presented a personality disorder. This student was quarrelsome, having difficulties with colleagues, professors and advisors. Another important situation was the high percentage of subjects who made reference to suicide ( $18 \%$ of the graduate students had at some point considered suicide). As is acknowledged, this tendency towards selfdestruction is prevalent among professionals within the health area, particularly physicians (3). As mentioned earlier, the present mental health program was established after the suicide of four young physicians. The institutional impact of those deaths was extremely strong. This impact contributed greatly to the creation of the program and to greater sensitivity of the university regarding the mental health of professionals who are undergoing graduate training. In this context, it gradually became possible to broaden and deepen the discussion of these matters. It is known that stigma is associated with mental health problems, which may deter sufferers from seeking help (14). The mental health program is part of a general care unit at a site far from the university campus. Moreover, there is an atmosphere of trust and confidentiality, which may be responsible for the high adherence to the program. However, it is expected that students of higher socioeconomic level will seek private care.

On the basis of the experience of psychological/psychiatric follow-up of the students seen in the program, we can describe two basic types of crises: 1) situational-adaptive - a personal as well as professional crisis, triggered by emotional conflicts related to personal development and stressful events resolution of issues that are typical of that age bracket and the individual's life itself, such as the beginning/consolidation/break up of an affective relationship. This also includes the professional or academic conflict with advisors, colleagues and professors, and economic difficulties; 2) psychopathological crisis - in which the difficulties experienced by an individual, personal as well as professional and academic, are the 
result of identifiable psychopathological situations that could be triggered in students more vulnerable to developing psychiatric disorders.

With the objective of integrating the observations in care or assistance with those acquired through the teaching and training of undergraduate and graduate students, we propose that the psychiatric suffering of students (and perhaps, partially, of advisors), and all its related problems, come both from the workplace and from the individual and can be grouped into three categories: a) professional stress - linked to the vicissitudes inherent to building the career of a researcher in an environment that is more and more competitive (publish or perish) in a situation characterized by the progressive dwindling of research funding; b) situational stress associated with the pressures and demands of graduate training, such as time pressure (deadlines), difficulties in personal relationships (advisors, professors, colleagues) arising in part from the competitive environment that permeates working relationships, academic activities (patient assistance, classes, scientific production), the quality of teaching and the learning environment; c) personal stress - linked to individual characteristics and personal traits and situations, such as gender, personality characteristics, personal or family history of psychiatric disorders, psychological vulnerability (a greater or lesser difficulty in dealing with interpersonal conflicts, for example, situations such as rivalry and professional competition), social and economic situation (managing personal and family financial needs), family problems, and life events.

On the basis of the possible impact of graduate training on the mental health of students, it is important to implement a series of political and institutional measures. In the broader realm of society, political measures include creating organized move- ments to pressure universities and scientific entities to pressure the government to increase funding destined to the fellowships of students and to their research. In the institutional sphere of graduate programs, measures to foster health, which include the awareness of students, professors and advisors regarding graduate training stress, might well facilitate the early detection of students with emotional disorders and academic dysfunctions. Such awareness can also contribute to building a learning environment that will be more prone to receive or accept students with difficulties and psychosocial vulnerabilities. The creation of mental health programs for the student community is another viable measure, especially for students who lack the financial resources to obtain psychiatric care. Studies and research with graduate students, postdoctoral fellows and professors of graduate programs in different areas of knowledge should be stimulated to contribute data that will enhance the present training system for faculty and researchers. If we consider the expressive growth in Brazilian scientific production resulting from the implementation of the national graduate system, the main idea is to stimulate efforts to improve the system.

It is important to highlight that Brazilian public universities (state and federal) do not charge student registration or any other academic fees and that approximately $90 \%$ of the scientific production of Brazil, as well as the training of specialists, Master's, Doctoral, and Postdoctoral students in Biomedical Science take place in public universities.

\section{Acknowledgments}

The authors would like to thank an anonymous referee of the journal for his/her comments, which helped to improve the quality of this paper. 


\section{References}

1. Firth-Cozens J (2003). Doctors: their well being and their stress. British Medical Journal, 326: 670-671.

2. Nogueira-Martins LA (2002). Saúde mental dos profissionais de saúde. In: Botega NJ (Editor), Prática Psiquiátrica no Hospital Geral: Interconsulta e Emergência. Artmed Editora, Porto Alegre, RS, Brazil.

3. Center C, Davis M, Detre T et al. (2003). Confronting depression and suicide in physicians - a consensus statement. Journal of the American Medical Association, 289: 3161-3166.

4. Nogueira-Martins LA \& Jorge MR (1998). Natureza e magnitude do estresse na Residência Médica. Revista da Associação Médica Brasileira, 44: 28-34.

5. Toews JA, Lockyer JM, Dobson DJG, Simpson E, Brownnell AKW, Brenneis F, MacPherson KM \& Cohen GS (1997). Analysis of stress levels among medical students, residents, and graduate students at four Canadian schools of medicine. Academic Medicine, 72: $997-$ 1002.

6. Louzada R \& Silva Filho JF (2002). Sofrimento psíquico e formação de pesquisadores. Revista Brasileira de Psiquiatria, 24 (Suppl II): 128.

7. de Meis L, Velloso A, Lannes D, Carmo MS \& de Meis C (2003). The growing competition in Brazilian science: rites of passage, stress and burnout. Brazilian Journal of Medical and Biological Research, 36: 1135-1141.

8. Nogueira-Martins LA (1994). Residência Médica: um estudo prospectivo sobre dificuldades na tarefa assistencial e fontes de estresse. Doctoral thesis, Departamento de Psiquiatria, Escola Pau- lista de Medicina, Universidade Federal de São Paulo, São Paulo, SP, Brazil.

9. Borenstein DB (1985). Should physician training centers offer formal psychiatric assistance to the house officer? A report on the major findings of a prototype program. American Journal of Psychiatry, 142: 1053-1057.

10. Nogueira-Martins LA, Stella RCR \& Nogueira HE (1997). A pioneering experience in Brazil: the creation of a center for assistance and research for medical residents (NAPREME) at the Escola Paulista de Medicina, Federal University of São Paulo. São Paulo Medical Journal, 115: 1570-1574.

11. Mari JJ, lacoponi E, Williams P, Simões O \& Silva JB (1987). Detection of psychiatric morbidity in the primary care setting in Brazil. Revista de Saúde Pública, 21: 501-507.

12. Almeida-Filho N, Mari JJ, Coutinho E, França JF, Fernandes JG, Andreoli SB \& Busnello EA (1992). Estudo multicêntrico de morbidade psiquiátrica em áreas urbanas brasileiras (Brasília, São Paulo, Porto Alegre). Revista da Associação Brasileira de Psiquiatria Asociación Psiquiátrica de la América Latina, 14: 93-104.

13. Mari JJ, Almeida N, Coutinho E, Andreoli SB, Miranda CT \& Streiner DL (1993). The epidemiology of the use of psychotropics in the city of São Paulo. Psychological Medicine, 23: 467-474.

14. Chew-Graham CA, Rogers A \& Yassin N (2003). 'I wouldn't want it on my CV or their records': medical students' experiences of helpseeking for mental health problems. Medical Education, 37: 873880 . 